\title{
Adopting Gayet's Techniques of Totally Laparoscopic Liver Surgery in the United States
}

\author{
Andrew A. Gumbs ${ }^{a}$ Brice Gayet ${ }^{b}$ \\ aDepartment of Surgical Oncology, Summit Medical Group, Berkeley Heights, N.J., USA; \\ ${ }^{b}$ Department of Digestive Diseases, Institut Mutualiste Montsouris, Paris, France
}

\section{Key Words}

Minimally invasive $\cdot$ Hepatectomy $\cdot$ Laparoscopic $\cdot$ Liver resection

\begin{abstract}
Professor Brice Gayet of the Institut Mutualiste Montsouris in Paris, France, has developed totally laparoscopic techniques for all segments of the liver. As a pioneer in the field of minimally invasive hepato-pancreato-biliary surgery, he started a Minimally Invasive Hepato-Pancreato-Biliary Fellowship in 2006. A retrospective review of all hepatic cases performed by a single surgeon since completing this Fellowship was undertaken. From November 2007 to October 2012, a total of 80 liver resections were done, of which 73 were begun with the intention of completing the case laparoscopically. Of these, more than $90 \%$ were completed laparoscopically and $88 \%$ were for malignant disease. One of the foundations of Professor Gayet's techniques is the low lithotomy or 'French' position and the utilization of a small robotically controlled laparoscope holder that is sterilizeable and considerably more economic than complete surgical systems. Prototypes exist of robotically controlled hand-held laparoscopic instruments that, unlike the complete surgical system, enable surgeons to maintain a sense of touch (haptics). Proper training in minimally invasive hepato-pancreato-biliary techniques can be obtained with surgeons able to independently perform laparoscopic major hepatectomies without senior minimally invasive backup. Furthermore, miniature and more affordable robotics may enable more surgeons to enjoy the benefits of minimally invasive surgery while maintaining patient safety and minimizing the rising burden of health-care costs worldwide.
\end{abstract}




\section{Liver Cancer}

\section{Introduction}

In the United States, the vast majority of liver surgery is still done via open techniques. of the limited centers that employ minimally invasive techniques for liver surgery, the majority only utilize laparoscopic surgery for ablations [1-4]. When anatomic and nonanatomic liver resections are attempted, most minimally invasive liver surgeons in the US use multiple laparoscopic vascular GIA stapler firings to come across the hepatic parenchyma [5-8]. This may be because GIA stapler devices though not invented in the US became popularized by American industry.

Working in France in a socialized health-care system, Professor Brice Gayet developed techniques of totally laparoscopic liver surgery in the early to mid-1990s using as many reusable devices as possible and limiting staple firings to 1 for the hepatic vein [9-11]. By controlling the hepatic inflow extraparenchymally in the hepatoduodenal ligament and actually dissecting out segmental branches in the hepatic parenchyma, Gayet developed totally laparoscopic methods for hepatectomy to all segments of the liver [12]. To do this, the liver parenchyma is divided by using laparoscopic ultrasonic shears, with clips placed on segmental vessels larger than $5 \mathrm{~mm}$.

Professor Gayet began offering a Minimally Invasive Hepato-Pancreato-Biliary Fellowship in 2006 in an effort to disseminate his techniques internationally [13]. The fellowship has been listed on the International Hepato-Pancreato-Biliary Association's (IHPBA) website as an approved IHPBA fellowship since 2007. Professor Gayet also has a $\mathrm{PhD}$ in anatomy and, as with all of his procedures, the successful execution of them depends on a complete mastery of anatomy. As Professor Gayet's first Minimally Invasive HepatoPancreato-Biliary Fellow, I have had the unique opportunity of bringing Gayet's techniques back to the United States. One of the hallmarks of Professor Gayet's techniques is the utilization of a robotically controlled laparoscope holder [14]. This allows the operating surgeon to stand in-between the patients legs in the so-called 'French' position and maintain contact with the patient. Other robotically assisted techniques have the operating surgeon working at a console several feet away from the actual patient and not sterile, potentially delaying conversion to an open approach if uncontrollable hemorrhage develops [15-18].

\section{Methods}

All patient data were recorded prospectively and reviewed retrospectively. All liver resections performed as the primary surgeon were analyzed, and liver biopsies and ablations were excluded. All surgeries begun with the intention of completing the case laparoscopically were considered minimally invasive even if conversion to an open procedure was ultimately required. As in previous reports, outcome measures included patient age, tumor size, estimated blood loss, length of hospitalization, type of hepatic resection done, margin status, morbidity, mortality and follow-up. Major resections were defined as a removal of 3 or more segments, and minor resections were all resections of less than 3 hepatic segments.

Operative Technique

Setup and Trocars

To perform Gayet's approach to laparoscopic liver resection, all patients are placed in the low lithotomy or 'French' position after general endotracheal anesthesia is obtained [9-11]. A safety strap is placed, all bony prominences are given extra padding, and all patients have compression boots placed on their lower extremities. Preoperatively, patients also receive 5,000 U of subcutaneous heparin to further reduce the risk of deep venous thrombosis and intravenous antibiotics. Pneumoperitoneum to 15 torr is obtained with the Hasson technique one handbreadth $(8 \mathrm{~cm})$ below the right subcostal margin along the midclavicular line for the laparoscope. 


\section{Liver Cancer}

\begin{tabular}{l|l}
\hline \multicolumn{2}{l}{ Liver Cancer 2013;2:5-15 } \\
\hline $\begin{array}{l}\text { DOI: 10.1159/000346213 } \\
\text { Published online: January 7, } 2013\end{array}$ & $\begin{array}{l}\text { ( 2)13 S. Karger AG, Basel } \\
\text { www.karger.com/lic }\end{array}$ \\
\hline
\end{tabular}

Gumbs et al:: Adopting Gayet's Techniques of Totally Laparoscopic Liver Surgery in the United States

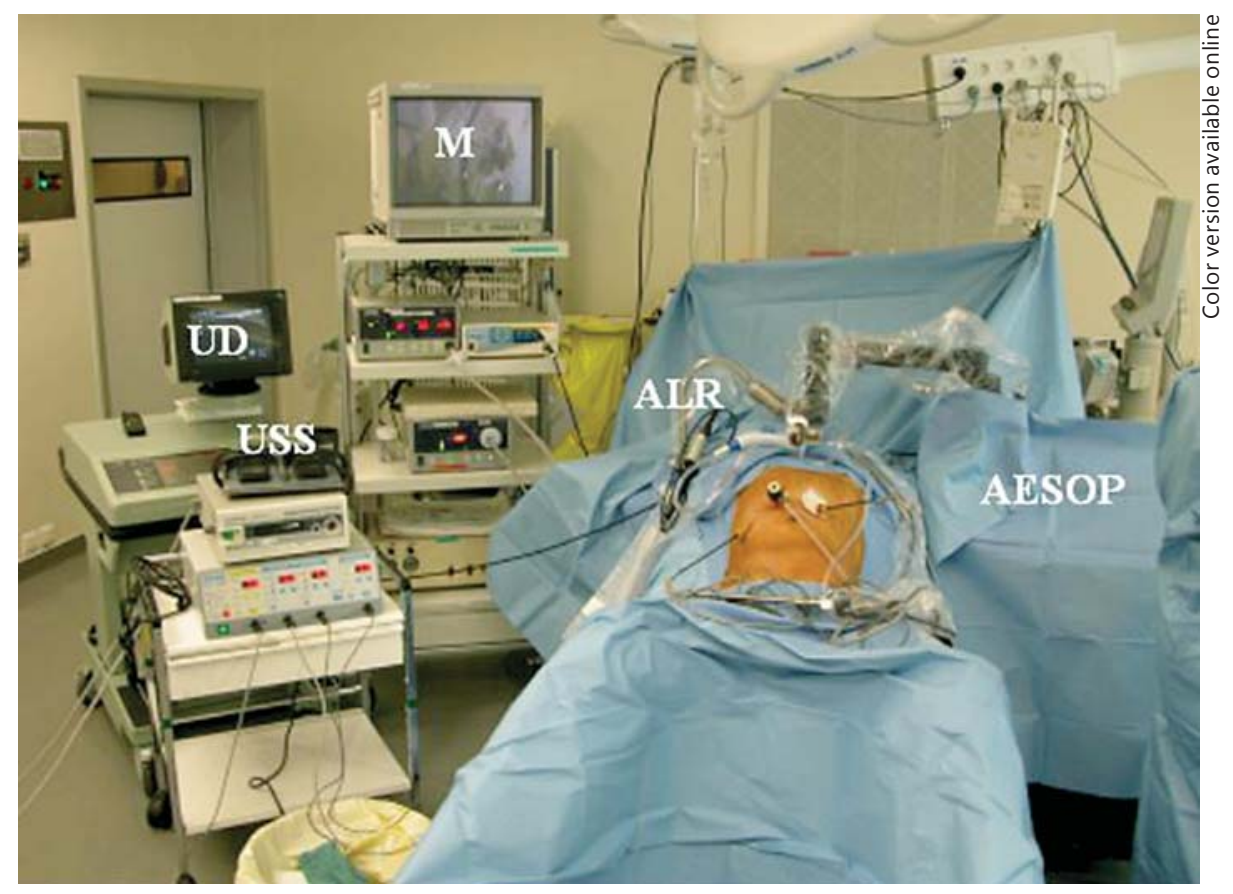

Fig. 1. Professor Brice Gayet's operating room setup with the patient in low lithotomy or the 'French' position with the surgeons standing in-between the patient's legs. High-definition monitors (M) are placed at the head of the bed to the patient's right. Laparoscopic ultrasound devices (UD), laparoscopic ultrasonic shears (USS) and autostatic liver retractors (ALR) are available routinely. AESOP (Intuitive), a robotically controlled camera holder, is placed to the patient's left.

A 12-mm balloon-tipped blunt trocar is placed into the abdomen, and a diagnostic laparoscopy is undertaken to rule out carcinomatosis and undiagnosed malignant ascites. In obese patients, the Veress needle is used to obtain pneumoperitoneum to 20 torr. The optic trocar is then placed at the abovementioned site. Two penetrating working trocars measuring $12 \mathrm{~mm}$ are then placed to the left and the right of the optic trocar under direct visualization. For minor hepatectomies, a 5-mm trocar is placed one handbreadth below the costal margin along the right anterior axillary line for right-sided lesions and in the left upper quadrant for left-sided lesions. For major hepatectomies, 12-mm trocars are placed in both locations and used mainly for liver retraction; a sixth trocar also measuring $12 \mathrm{~mm}$ is placed towards the end of the procedure just below the right subcostal margin along the midclavicular line which is used to transect the hepatic veins with a laparoscopic vascular GIA device. Twelve-millimeter trocars are used for all of the ports so that staplers can be introduced at the maximal number of angles. The robotically controlled laparoscope holder is then placed to the left of the patient if the AESOP (Intuitive, Sunnyvale, Calif., USA; fig. 1) is used, or to the patient's right if the ViKY device (Endocontrol, Grenoble, France; fig. 2a, b) is used for lesions in the right lobe or to the patient's left for left-sided lesions.

\section{Dissection of the Hepatoduodenal Ligament}

Gayet originally described complete isolation and transection of the hepatic arteries, portal venous branches and bile ducts. It is still imperative to perform resections in this manner early in one's experience to master the hepatic anatomy and become comfortable with anatomic variants so that lesions close to the confluence can be addressed. However, now only the hepatic inflow is controlled extraparenchymally. The hepatic arteries can be controlled exclusively with laparoscopic clips and can then be transected, but delayed hemorrhage from portal venous branches has been reported after clipping alone (fig. 3). Because of this, clips placed on the portal vein branches must be oversewn with 4.0 prolene. As laparoscopic vascular GIA staplers are more readily available in the United States and operating room time is the main 


\section{Liver Cancer}

\begin{tabular}{l|l}
\hline Liver Cancer 2013;2:5-15 \\
\hline DOI: 10.1159/000346213 & $\begin{array}{l}\text { ( ) 2013 S. Karger AG, Basel } \\
\text { www.karger.com/lic }\end{array}$ \\
Published online: January 7, 2013 &
\end{tabular}

Gumbs et al.: Adopting Gayet's Techniques of Totally Laparoscopic Liver Surgery in the United States

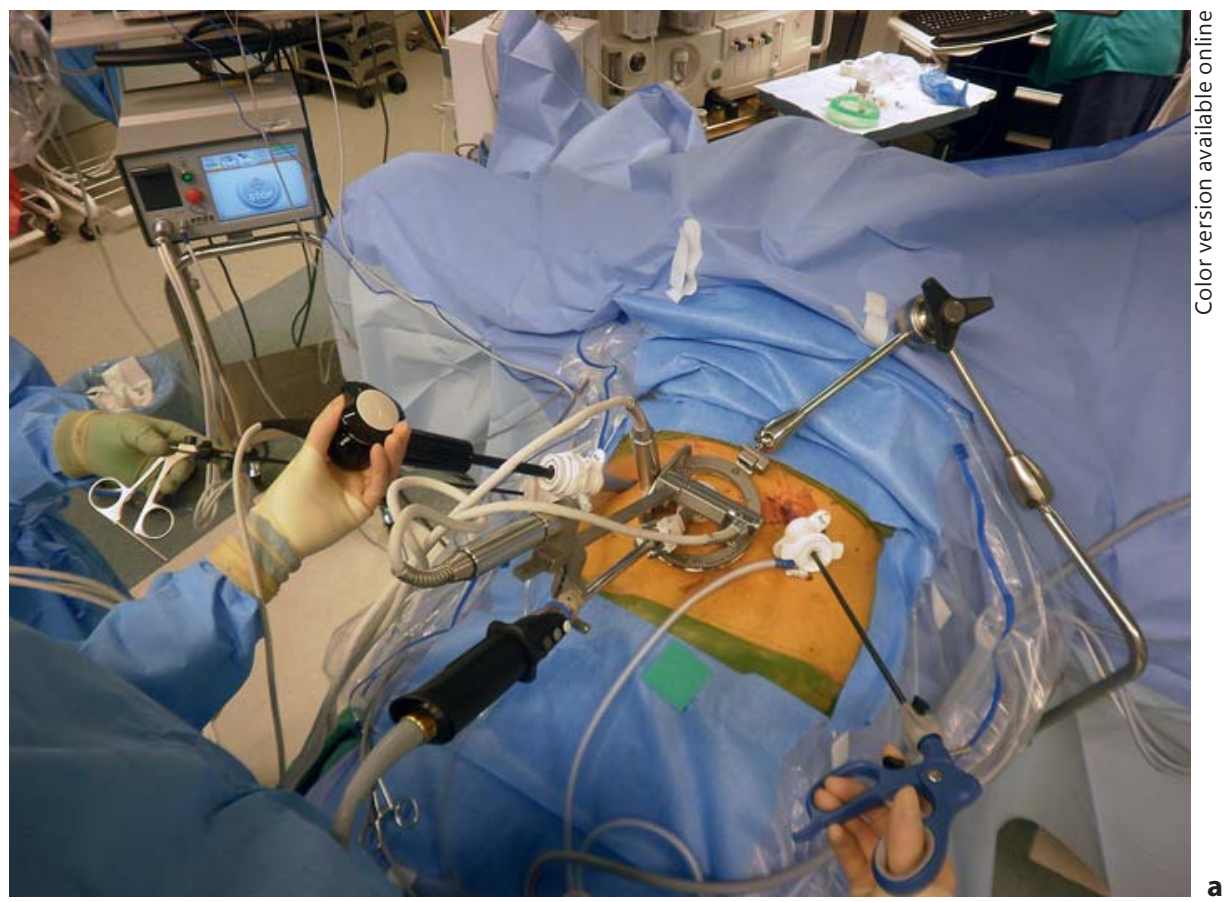

Fig. 2. a Operating room setup in the United States with an autoclaveable robotically controlled laparoscope holder (ViKY, Endocontrol) placed to the patient's left for a left-sided hepatic lesion. b ViKY console, ViKY (Video endosKopY) and the foot pedal.

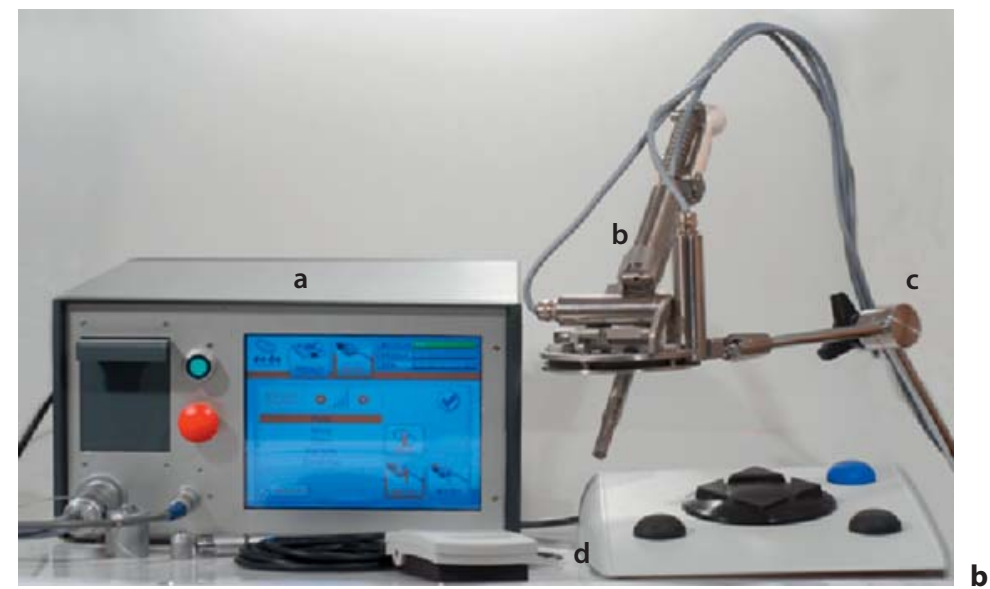

limiting factor, the portal vein branches are preferentially transected with a laparoscopic stapler (fig. 4a, b). Due to the increased risk of damaging the contralateral bile duct, and if possible, the left or right hepatic duct is taken with a laparoscopic GIA stapler within the hepatic parenchyma (fig. 5) [19].

\section{Parenchymal Transection}

Although laparoscopic left lateral segmentectomies should initially be done by isolating the arterial and venous blood supply and by performing the parenchymal transection with laparoscopic ultrasonic shears, laparoscopic clips and a bipolar device so that the intraparenchymal anatomy of segments II and III can be understood, this resection can be done faster, with essentially no blood loss, by using sequential firings of the laparoscopic vascular GIA stapler. To do this, the first $1 \mathrm{~cm}$ of the hepatic parenchyma just to the patient's left of the falciform is transected with the ultrasonic shears to thin the transection line; then, the resection is completed with usually about 3 laparoscopic stapler firings of the 60 -mm vascular cartridge.

For major hepatectomies, the retrohepatic veins larger than $5 \mathrm{~mm}$ draining into the inferior vena cava should be clipped prior to transection (fig. 6), and some larger vessels may need to be transected with the laparoscopic vascular stapler device. The hepatic parenchyma is then transected with a combination of 


\section{Liver Cancer}

\begin{tabular}{l|l}
\hline Liver Cancer 2013;2:5-15 & $\begin{array}{l}\text { ( ) 2013 S. Karger AG, Basel } \\
\text { www.karger.com/lic }\end{array}$ \\
\hline DOI: 10.1159/000346213 & Published online: January 7, 2013
\end{tabular}

Gumbs et al.: Adopting Gayet's Techniques of Totally Laparoscopic Liver Surgery in the United States

Fig. 3. Laparoscopic dissection of the hepatoduodenal ligament: the proper hepatic artery (PHA), right hepatic artery (RHA) and left hepatic artery (LHA) are shown.
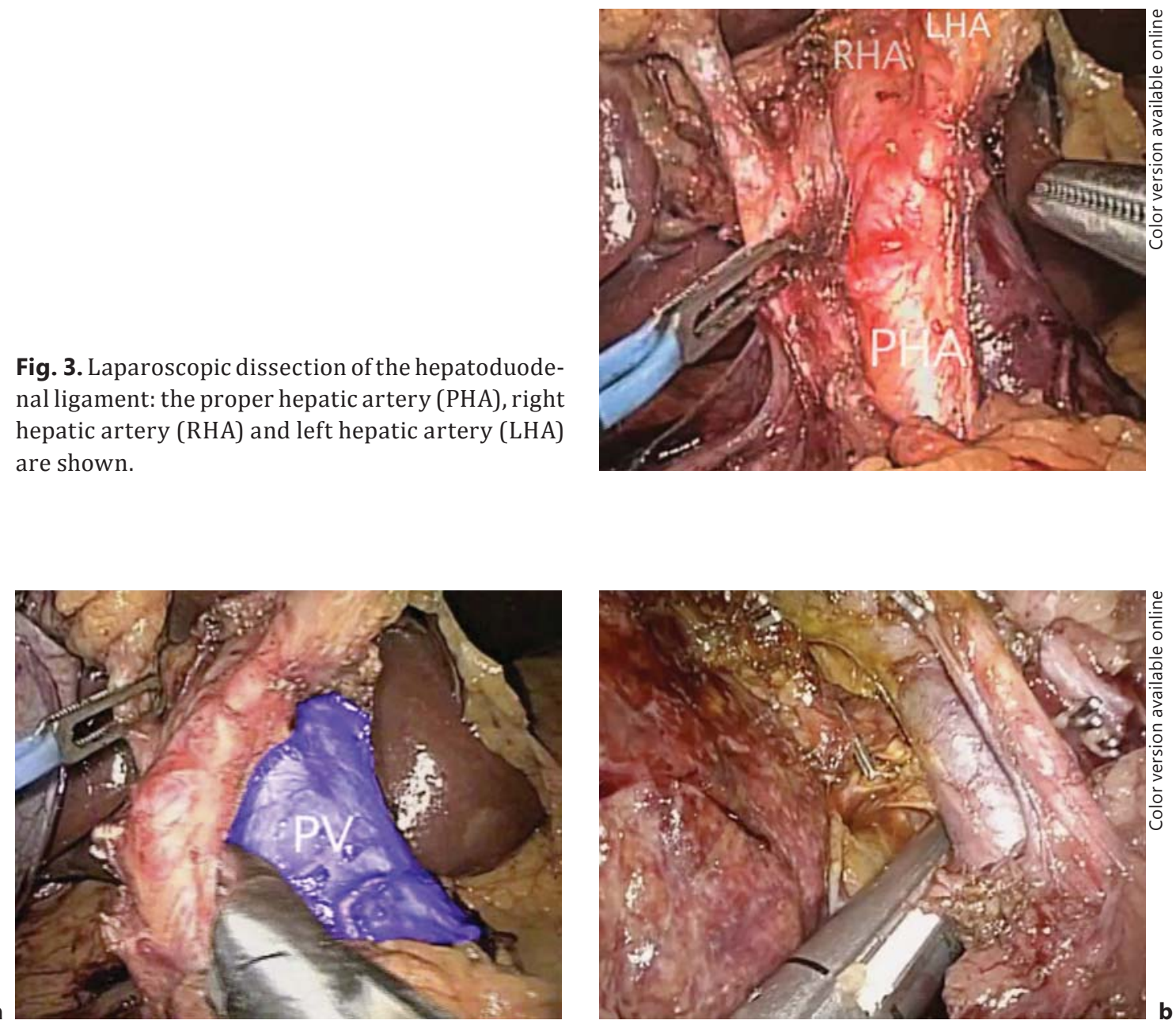

Fig. 4. Laparoscopic dissection of the hepatoduodenal ligament. a Dissection of the hepatic artery off of the portal vein (PV) is shown in blue. b Laparoscopic transection of the posterior branch of the right portal vein with a laparoscopic vascular GIA stapler device.

Fig. 5. Intrahepatic transection of the right hepatic duct after extraparenchymal transection of the hepatic vascular inflow to the right hepatic lobe.

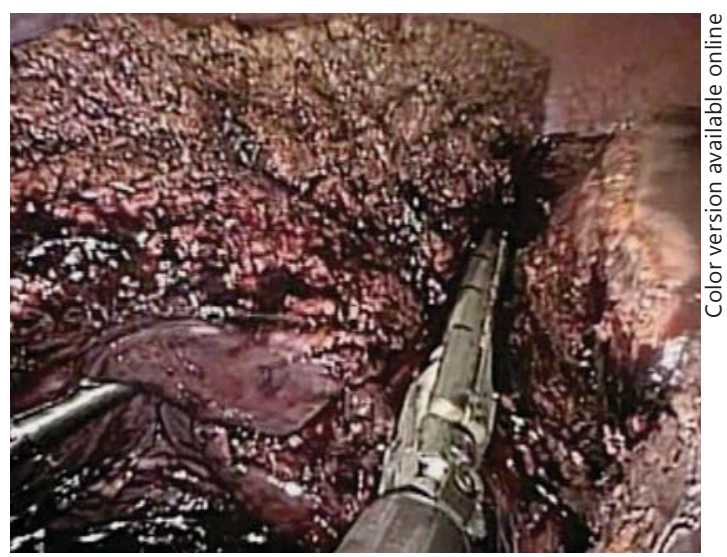




\section{Liver Cancer}

\begin{tabular}{|c|c|}
\hline r 2013;2:5-15 & \\
\hline $\begin{array}{l}\text { DOI: } 10.1159 / 000346213 \\
\text { Published online: January 7, } 2013\end{array}$ & $\begin{array}{l}\text { (c) } 2013 \text { S. Karger AG, Basel } \\
\text { www.karger.com/lic }\end{array}$ \\
\hline
\end{tabular}

Gumbs et al:: Adopting Gayet's Techniques of Totally Laparoscopic Liver Surgery in the United States

Fig. 6. Retrohepatic view of vein draining either hepatic 5 or 8 directly into the inferior vena cava. The vein is clipped prior to its transection; larger vessels may require transection with a laparoscopic vascular GIA stapler device.

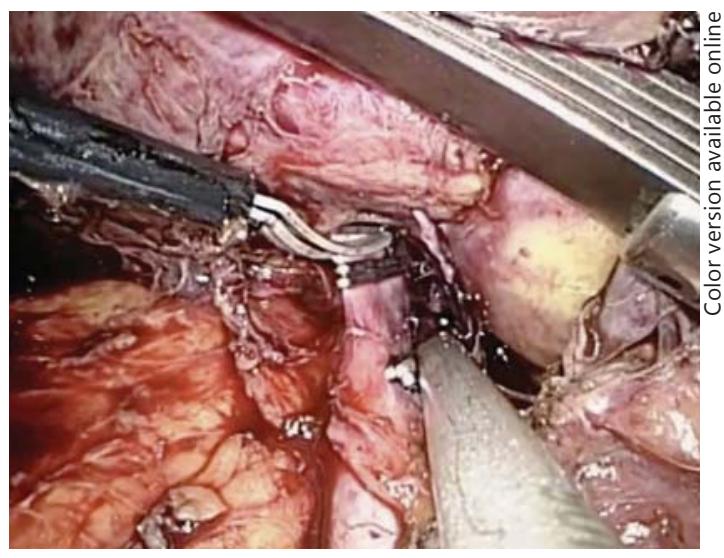

laparoscopic ultrasonic shears with hemostasis and laparoscopic bipolar forceps. The respective hepatic vein is then transected with the laparoscopic vascular stapler device. More detailed steps for totally laparoscopic major, extended major and central hepatectomies as well as the laparoscopic lateral approach for lesions in the deep segments have been extensively detailed and published elsewhere [9-12, 20].

\section{Results}

\section{Hepatectomies}

From November 2007 to October 2012, 80 liver resections were performed, of which 73 (91\%) were attempted laparoscopically. Seven (9\%) hepatectomies were begun via open techniques and have been reported elsewhere [21]. These patients were not included in this study. In addition, a total of 7 laparoscopic radiofrequency and 36 laparoscopic microwave ablations were done in 30 patients. These patients were not included in this study as well. Our results from our initial 50 patients who underwent laparoscopic liver resection for cancer were recently published [21].

\section{Laparoscopic Hepatectomies}

Among the cases attempted laparoscopically, 66 out of 73 (90\%) were completed totally laparoscopically, 4 (5\%) were laparoscopic-assisted procedures and $3(4 \%)$ had to be converted to a laparotomy. In total, 44 minor hepatectomies (24 bisegmentectomies and 20 segmentectomies or wedge resections) and 29 major hepatectomies (14 right hepatectomies, 11 left hepatectomies and 4 trisegmentectomies) were performed.

Sixty-four (88\%) patients were operated on for cancer. These included 17 primary tumors 12 gallbladder cancers, 4 hepatocellular carcinomas and 1 intrahepatic cholangiocarcinoma) and 47 secondary tumors (37 colorectal metastasis, 4 carcinoid tumor metastases, 2 anal cancer metastases, 1 endometrial cancer metastasis, 1 renal cell carcinoma metastasis, 1 breast cancer metastasis and 1 bladder cancer metastasis). The mean tumor size was $2.9 \mathrm{~cm}$ (range $=0.3-11.5$ ) for minor hepatectomies and $3.8 \mathrm{~cm}$ (range $=2.0-11.5$ ) for major hepatectomies.

\section{Laparoscopic Minor Hepatectomy}

The average age of the 44 patients who underwent a laparoscopic minor hepatectomy was 58 years (range $=31-84$ ). The indications were mainly for cancer, including 21 secondary tumors (15 colorectal metastases, 2 carcinoid tumor metastases, 2 anal cancer metastasis, 


\section{Liver
Cancer}

\begin{tabular}{|c|c|}
\hline \multicolumn{2}{|l|}{ Liver Cancer 2013;2:5-15 } \\
\hline $\begin{array}{l}\text { DOI: } 10.1159 / 000346213 \\
\text { Published online: January 7, } 2013\end{array}$ & $\begin{array}{l}\text { (c) } 2013 \text { S. Karger AG, Basel } \\
\text { www.karger.com/lic }\end{array}$ \\
\hline
\end{tabular}

1 metastasis from renal cell carcinoma and 1 endometrial cancer metastasis) and 15 primary hepatic tumors (12 gallbladder carcinomas and 3 hepatocellular carcinomas). The mean hospital stay was 4 days (range $=1-14$ ), and the mean operative time was $135 \mathrm{~min}$ (range = $60-480$ ). The mean estimated blood loss was $70 \mathrm{~cm}^{3}$ (range $\left.=0-800\right)$. One patient developed an ileus that was managed nonoperatively and resulted in an overall morbidity rate of $2 \%$; there were no major morbidities or mortalities at 30 days.

\section{Laparoscopic Major Hepatectomy}

The average age of the 29 patients who underwent laparoscopic major hepatectomy was 60 years (range $=37-87$ ). Surgery was done for cancer in all but 1 patient and included 26 secondary tumors (20 colorectal metastases, 2 carcinoid tumor metastases, 1 breast cancer metastasis and 1 bladder cancer metastasis) and 2 primary hepatic tumors (1 hepatocellular carcinoma and 1 cholangiocarcinoma). Five patients also underwent preoperative portal vein embolization. The mean operative time was $350 \mathrm{~min}$ (range $=150-620$ ), and the mean estimated blood loss was $360 \mathrm{~cm}^{3}$ (range $=50-4,100$ ). Complications occurred in 6 (21\%) patients and included 2 cases of hemorrhage requiring conversion to an open approach, 3 bile leaks, 1 incisional hernia requiring reoperation and 1 postoperative ileus managed nonoperatively. The 3 bile leaks resolved with percutaneous drainage; however, 1 patient also necessitated endoscopic placement of a biliary stent. Reoperations occurred in $3(10 \%)$ patients: two for second looks after uncontrollable hemorrhage early in the experience and the third for an incarcerated hernia in a patient with a 'swiss cheese' abdominal wall defect prior to undergoing a laparoscopic left hepatectomy.

\section{Discussion}

Minimally invasive approaches to liver resections have been performed since the 1990s and begin with ablative procedures and fenestrations, followed by minor resections, major hepatectomies, extended major hepatectomies and even central hepatectomies [22-24]. Initially, surgeons felt that only the inferior and peripheral segments of the liver could be approached laparoscopically; however, in 2007, Professor Gayet showed that all segments of the liver could be approached laparoscopically and that 'nonlaparoscopic' or deep segments might actually be indications for a minimally invasive approach [12, 25]. Multiple series extolling the benefits of minimally invasive hepatic surgery have been increasingly published from more and more centers with an emphasis on the efficacy and safety in cancer patients [26-28]. Benefits of the minimally invasive approach seem to be limited to short-term gains in the length of hospitalization, blood loss and narcotic usage. As with laparoscopic colon surgery, patients undergoing minimally invasive liver surgery for colorectal metastases seem to enjoy increased long-term survival when compared to open historical controls; however, longer and larger trials are still necessary [21, 29-31]. Authors have even shown that patients who have undergone previous open hepatectomy can enjoy the benefits of a minimally invasive approach [32]. Potential benefits in patients with hepatocellular carcinoma include decreased postoperative ascites, liver failure and lung complications [25, $29,33,34]$.

Since returning to the United States, over 70 minimally invasive hepatectomies have been performed, including minor and major hepatectomies. Using the principles of Professor Gayet's techniques, hepatic resections have been expanded to include laparoscopic partial diaphragm resections and repair with mesh (fig. 7). Additionally, over 12 patients have undergone either radical cholecystectomy or completion radical cholecystectomy with hepatoduodenal lymphadenectomy for gallbladder cancer using laparoscopic techniques (fig. 8a, 


\section{Liver Cancer}

Fig. 7. Right diaphragmatic defect after laparoscopic right hepatectomy and partial right diaphragm resection for a colorectal hepatic metastasis. The diaphragm is shown here being repaired laparoscopically in a primary fashion; mesh is then placed laparoscopically as a buttress.

Fig. 8. Laparoscopic view of a T3 gallbladder cancer that required laparoscopic common bile duct (CBD) excision (a) and Roux-en-Y choledochojejunostomy (b).

\begin{tabular}{l}
\hline \begin{tabular}{l}
\hline Liver Cancer 2013;2:5-15 \\
\hline DOI: 10.1159/000346213
\end{tabular} \\
\begin{tabular}{ll} 
Published online: January 7, 2013 & www.karger.com/lic \\
\hline Gumbs et al.: Adopting Gayet's Techniques of Totally Laparoscopic Liver Surgery in
\end{tabular}
\end{tabular}
Gumbs et al.: Adopting Gayet's Techniques of Totally Laparoscopic Liver Surgery in
the United States
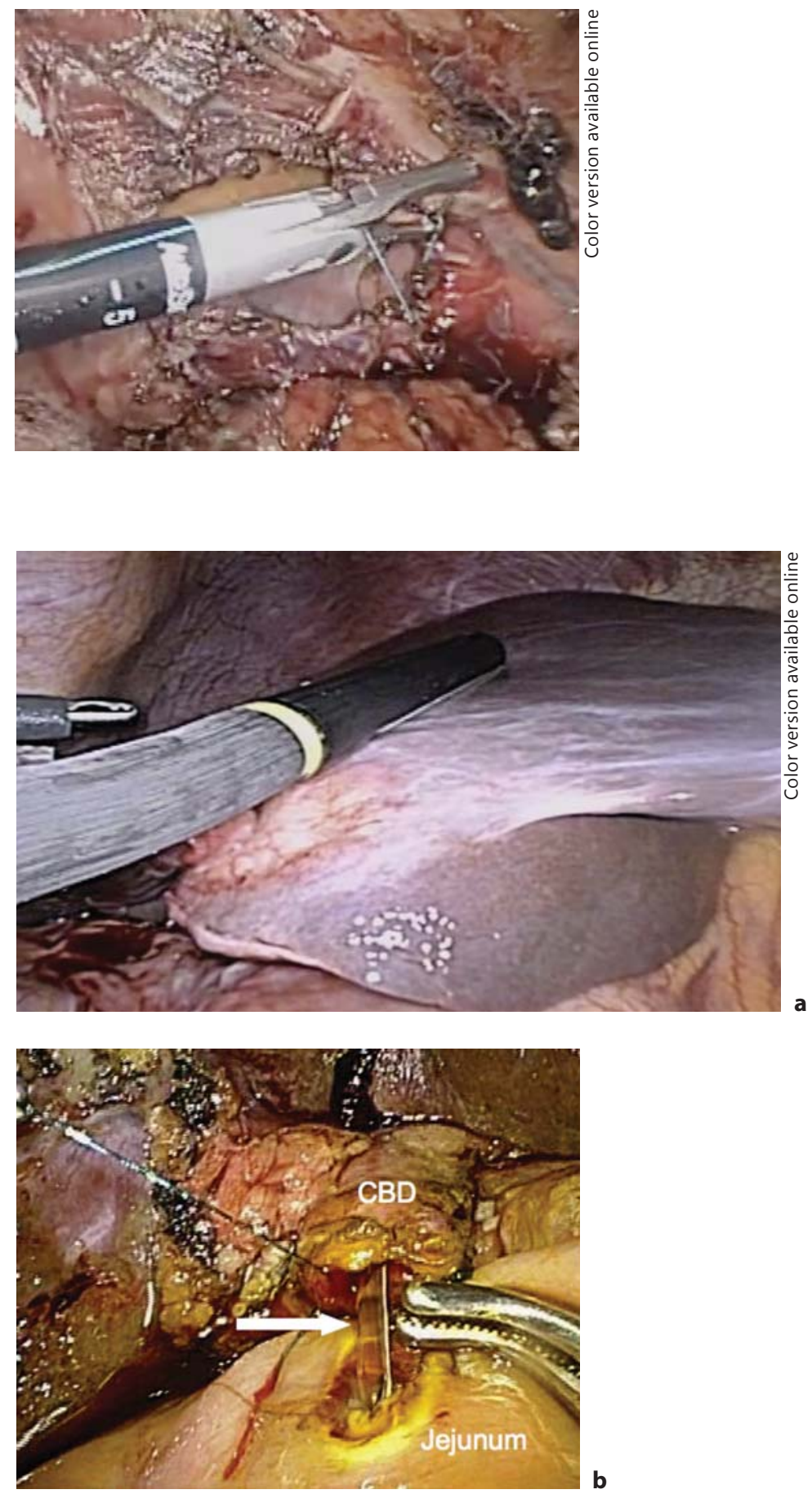

b) $[35,36]$. Minimally invasive surgery for the management of gallbladder cancer may be ideal before attempting formal laparoscopic major hepatectomy. Although it is important to be able to identify the left and right hepatic ducts, extraparenchymal transection may increase the risk of bile duct injury and is now done via intrahepatic transection [19].

As minimally invasive surgeons have continued to refine their techniques, numerous centers have even begun offering single-incision laparoscopic hepatectomy [37-42]. Al- 
Gumbs et al.: Adopting Gayet's Techniques of Totally Laparoscopic Liver Surgery in the United States

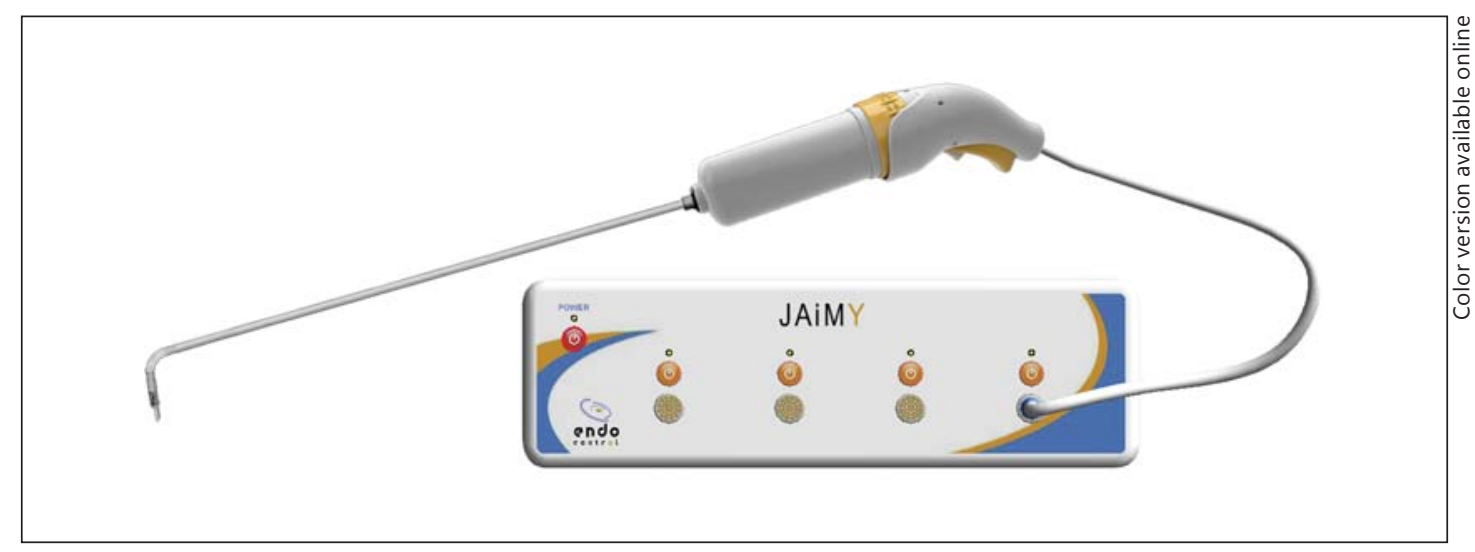

Fig. 9. Robotically controlled hand-held laparoscopic instruments (Jaimy, Endocontrol), that offer the benefits of robotics without sacrificing haptics.

though interesting intellectually, there do not seem to be any benefits over multitrocar laparoscopy, and the increased incision length required to perform this techniques makes its utility questionable for minor resections and puzzling for major resections where incisions are sometimes longer than after standard laparoscopy.

Because of the fine dissection that is required in the porta hepatis and the need to be able to suture effectively and potentially in a timely fashion while performing laparoscopic hepatectomies, surgeons were initially excited to use the complete surgical system (DaVinci, Intuitive); however, the lack of haptics led most minimally invasive surgeons to abandon this device [43]. Over the years, the complete surgical system has been more frequently utilized for minimally invasive procedures in the pelvis. This is due to the fact that laparoscopic procedures in this area are not always ergonomic because there is no place for the surgeon to stand and directly face the operative field. This limitation is not present for procedures in the upper abdomen. Patients can be placed in the low lithotomy (French) position, and surgeons can stand in-between patients legs and operate ergonomically. Nevertheless, having the assistant hold the camera for multiple hours, though feasible, is not an ideal situation.

To rectify this, robotically controlled laparoscopes have been around for several decades. Unfortunately, one of the earliest models was purchased by the company that makes the complete surgical system, and its production then halted. Smaller companies have developed robotically controlled laparoscopes that are sterilizable and can be put in contact with the patient and the sterile field [14, 21, 29]. By using a robotically assisted approach in this manner, surgeons can control what they are looking at, have a steady image and maintain contact with their patients. This has the potential to not delay conversion to open surgery when necessary but, more importantly, allows for a hand-assisted approach for difficult cases that would have to be otherwise converted to an open approach if a complete surgical system were utilized [21].

Smaller hand-held robotically controlled instruments are also being developed that increase the degrees of freedom of laparoscopic instruments but, at the same time, enable surgeons to maintain haptics or their sense of touch (fig. 9). Haptics may be particularly useful when sutures of delicate structure such as bile ducts are required or if vascular suturing is required. As these prototypes become available and surgeons gain experience with them, more complex biliary and vascular resections and reconstructions may become 
Gumbs et al.: Adopting Gayet's Techniques of Totally Laparoscopic Liver Surgery in the United States

possible by an increasing number of hepatic surgeons. Additionally, as health-care costs continue to rise and global economies continue to struggle, less expensive and smaller robotic devices may be more reasonable economically and potentially even safer for patients. Larger multicenter trials with longer-term follow-up are still needed.

\section{Conclusion}

Since the 1990s, Professor Gayet has painstakingly developed minimally invasive techniques for hepatectomies to all segments of the liver and has shown that even central and extended major hepatectomies are possible with totally laparoscopic techniques. Using his techniques, partial diaphragm resections for hepatic tumors with concern for invasion and subsequent primary repair of the diaphragmatic defect with mesh overlay have also been done in the United States. Additionally, Professor Gayet's techniques seem particularly suited for the surgical management of gallbladder cancer, either as initial surgery or after open or laparoscopic cholecystectomy. Although important during the learning curve, extraparenchymal dissection of the main biliary ducts may not be necessary and may increase the risk of bile duct injury. The utilization of a robotically controlled laparoscope holder and an operating room setup consisting of patients in the 'French' position enable laparoscopic liver surgeons to operating ergonomically, with the benefit of a steady image that they control and the maintenance of haptics. As robotically controlled hand-held instruments become available, more complex biliary and vascular procedures may become possible by increasing numbers of minimally invasive surgeons. The economic benefits of smaller hand-held robots may enable more surgeons to enjoy the benefits of robotics without compromising patient safety or significantly adding to the economic burden of modern health care.

\section{Conflict of Interest}

No conflicts of interest to disclose.

\section{References}

- 1 Lau KN, Swan RZ, Sindram D, et al: Hepatic tumor ablation: application in a community hospital setting. Surg Oncol Clin N Am 2011;20:455-466.

- 2 Iannitti DA, Dupuy DE, Mayo-Smith WW, et al: Hepatic radiofrequency ablation. Arch Surg 2002;137:422426; discussion 427.

- 3 Iannitti DA, Martin RC, Simon CJ, et al: Hepatic tumor ablation with clustered microwave antennae: the US Phase II trial. HPB (Oxford) 2007; 9:120-124.

4 Padma S, Martinie JB, Iannitti DA: Liver tumor ablation: percutaneous and open approaches. J Surg Oncol 2009;100:619-634.

- 5 Buell JF, Cherqui D, Geller DA, et al: The international position on laparoscopic liver surgery: The Louisville Statement, 2008. Ann Surg 2009;250:825-830.

- 6 Gumbs AA, Gayet B, Gagner M: Laparoscopic liver resection: when to use the laparoscopic stapler device. HPB (Oxford) 2008;10:296-303.

7 Buell JF, Thomas MJ, Doty TC, et al: An initial experience and evolution of laparoscopic hepatic resectional surgery. Surgery 2004;136:804-811.

8 Cannon RM, Brock GN, Marvin MR, et al: Laparoscopic liver resection: an examination of our first 300 patients. J Am Coll Surg 2011;213:501-507.

9 Gumbs AA, Gayet B: Multimedia article. Totally laparoscopic extended right hepatectomy. Surg Endosc 2008;22:2076-2077.

10 Gumbs AA, Gayet B: Totally laparoscopic left hepatectomy. Surg Endosc 2007;21:1221.

-11 Gumbs AA, Bar-Zakai B, Gayet B: Totally laparoscopic extended left hepatectomy. J Gastrointest Surg 2008; 12:1152. 
Gumbs et al.: Adopting Gayet's Techniques of Totally Laparoscopic Liver Surgery in the United States

12 Gumbs AA, Gayet B: Video: the lateral laparoscopic approach to lesions in the posterior segments. J Gastrointest Surg 2008;12:1154.

13 Gumbs AA, Gayet B: The Medical and Surgical Department of Digestive Diseases and Minimally Invasive HPB Fellowship at IMM. HPB (Oxford) 2007;9:470-471.

14 Gumbs AA, Crovari F, Vidal C, et al: Modified robotic lightweight endoscope (ViKY) validation in vivo in a porcine model. Surg Innov 2007;14:261-264.

15 Ji WB, Wang HG, Zhao ZM, et al: Robotic-assisted laparoscopic anatomic hepatectomy in China: initial experience. Ann Surg 2011;253:342-348.

16 Kitisin K, Packiam V, Bartlett DL, et al: A current update on the evolution of robotic liver surgery. Minerva Chir 2011;66:281-293.

17 Vasile S, Sgarbura 0, Tomulescu V, et al: The robotic-assisted left lateral hepatic segmentectomy: the next step. Chirurgia (Bucur) 2008;103:401-405.

-18 Holloway RW, Brudie LA, Rakowski JA, et al: Robotic-assisted resection of liver and diaphragm recurrent ovarian carcinoma: description of technique. Gynecol Oncol 2011;120:419-422.

19 Tsai TJ, Chouillard EK, Gumbs AA: Laparoscopic right hepatectomy with intrahepatic transection of the right bile duct. Ann Surg Oncol 2012;19:467-468.

20 Gumbs AA, Gayet B: Totally laparoscopic central hepatectomy. J Gastrointest Surg 2008;12:1153.

21 Gumbs AA, Tsai TJ, Hoffman JP: Initial experience with laparoscopic hepatic resection at a comprehensive cancer center. Surg Endosc 2012;26:480-487.

22 Gagner M, Rogula T, Selzer D: Laparoscopic liver resection: benefits and controversies. Surg Clin North Am 2004;84:451-462.

23 Chouillard E, Gumbs A, Fangio P, et al: Liver resection for cystic lesions: a 15-year experience. Minerva Chir 2010;65:495-506.

-24 Buell JF, Tranchart H, Cannon R, et al: Management of benign hepatic tumors. Surg Clin North Am 2010;90: 719-735.

25 Cherqui D, Laurent A, Tayar C, et al: Laparoscopic liver resection for peripheral hepatocellular carcinoma in patients with chronic liver disease: midterm results and perspectives. Ann Surg 2006;243:499-506.

26 Tzanis D, Shivathirthan N, Laurent A, et al: European experience of laparoscopic major hepatectomy. J Hepatobiliary Pancreat Sci 2012, E-pub ahead of print.

-27 Abu Hilal M, Di Fabio F, Abu Salameh M, et al: Oncological efficiency analysis of laparoscopic liver resection for primary and metastatic cancer: a single-center UK experience. Arch Surg 2012;147:42-48.

-28 Castaing D, Vibert E, Ricca L, et al: Oncologic results of laparoscopic versus open hepatectomy for colorectal liver metastases in two specialized centers. Ann Surg 2009;250:849-855.

29 Vibert E, Perniceni T, Levard H, et al: Laparoscopic liver resection. Br J Surg 2006;93:67-72.

-30 Buell JF, Thomas MT, Rudich S, et al: Experience with more than 500 minimally invasive hepatic procedures. Ann Surg 2008;248:475-486.

-31 Cherqui D: Laparoscopic liver resection. Br J Surg 2003;90:644-646.

-32 Shafaee Z, Kazaryan AM, Marvin MR, et al: Is laparoscopic repeat hepatectomy feasible? A tri-institutional analysis. J Am Coll Surg 2011;212:171-179.

-33 Abu Hilal M, Di Fabio F, Wiltshire RD, et al: Laparoscopic liver resection for hepatocellular adenoma. World J Gastrointest Surg 2011;3:101-105.

-34 Cherqui D, Laurent A, Mocellin N, et al: Liver resection for transplantable hepatocellular carcinoma: longterm survival and role of secondary liver transplantation. Ann Surg 2009;250:738-746.

-35 Gumbs AA, Hoffman JP: Laparoscopic radical cholecystectomy and Roux-en-Y choledochojejunostomy for gallbladder cancer. Surg Endosc 2010;24:1766-1768.

-36 Gumbs AA, Hoffman JP: Laparoscopic completion radical cholecystectomy for T2 gallbladder cancer. Surg Endosc 2010;24:3221-3223.

37 Hu MG, Zhao GD, Xu DB, et al: Transumbilical single-incision laparoscopic hepatectomy: an initial report. Chin Med J (Engl) 2011;124:787-789.

-38 Cai XJ, Zhu ZY, Liang X, et al: Single incision laparoscopic liver resection: a case report. Chin Med J (Engl) 2010;123:2619-2620.

39 Gaujoux S, Kingham TP, Jarnagin WR, et al: Single-incision laparoscopic liver resection. Surg Endosc 2011; 25:1489-1494.

40 Kobayashi S, Nagano H, Marubashi S, et al: A single-incision laparoscopic hepatectomy for hepatocellular carcinoma: initial experience in a Japanese patient. Minim Invasive Ther Allied Technol 2010;19:367-371.

41 Pan MX, Jiang ZS, Cheng Y, et al: Single-incision laparoscopic hepatectomy: a case report. Surg Laparosc Endosc Percutan Tech 2011;21:e260-e262.

-42 Barbaros U, Sumer A, Tunca F, et al: Our early experiences with single-incision laparoscopic surgery: the first 32 patients. Surg Laparosc Endosc Percutan Tech 2010;20:306-311.

43 Vibert E, Denet C, Gayet B: Major digestive surgery using a remote-controlled robot: the next revolution. Arch Surg 2003;138:1002-1006. 